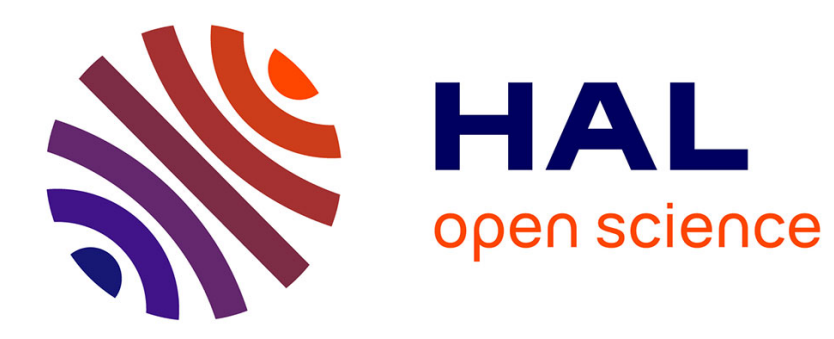

\title{
Anelastic Relaxations in Aluminium with Ultrafine Grain Structure
}

E. Bonetti, L. Pasquini, E. Sampaolesi, M. Alvisi

\section{To cite this version:}

E. Bonetti, L. Pasquini, E. Sampaolesi, M. Alvisi. Anelastic Relaxations in Aluminium with Ultrafine Grain Structure. Journal de Physique IV Proceedings, 1996, 06 (C8), pp.C8-345-C8-348. 10.1051/jp4:1996874 . jpa-00254682

\section{HAL Id: jpa-00254682 https://hal.science/jpa-00254682}

Submitted on 1 Jan 1996

HAL is a multi-disciplinary open access archive for the deposit and dissemination of scientific research documents, whether they are published or not. The documents may come from teaching and research institutions in France or abroad, or from public or private research centers.
L'archive ouverte pluridisciplinaire HAL, est destinée au dépôt et à la diffusion de documents scientifiques de niveau recherche, publiés ou non, émanant des établissements d'enseignement et de recherche français ou étrangers, des laboratoires publics ou privés. 


\title{
Anelastic Relaxations in Aluminium with Ultrafine Grain Structure
}

\author{
E. Bonetti, L. Pasquini, E. Sampaolesi and M. Alvisi* \\ Dipartimento di Fisica, Università di Bologna and Istituto Nazionale per la Fisica della Materia, Viale Berti \\ Pichat 6/2, 40127 Bologna, Italy \\ * Istituto Nazionale per la Fisica della Materia, Dipartimento di Scienza dei Materiali, Via Amesano, \\ 73100 Lecce, Italy
}

\begin{abstract}
The elastic energy dissipation coefficient and dynamic elasticity modulus were measured in the 3-4000 $\mathrm{Hz}$ frequency range by an inverted torsion pendulum and a vibrating reed technique on nanocrystalline aluminium samples obtained by mechanical attrition. The anelasticity spectra in the $300-700 \mathrm{~K}$ range on as-prepared samples with average grain size in the $20-40 \mathrm{~nm}$ range strongly depends on low temperature annealing treatments. A relaxational damping peak $\mathrm{P}_{1}$ at $460 \mathrm{~K}(3 \mathrm{~Hz})$ is observed in samples after thermal annealing without appreciable grain growth. A second peak P2 located at higher temperatures occurs when the grain size exceeds $100 \mathrm{~nm}$.
\end{abstract}

\section{INTRODUCTION}

The structure of nanophase materials on different length scales may significantly alter their physical properties and in particular the mechanical ones [1]. Two structural parameters are of major concern, the crystallites whose dimensions are typically in the $10-100 \mathrm{~nm}$ range and the large number of interfacial regions, constituting an appreciable volume fraction of the materials. Other structural features, some of which are strictly linked to the synthesis technique, may affect the behaviour of materials.

The atomic structure of the interfaces in nanophase materials, has been the object of several debates in these last years, starting from the early research works [2,3] suggesting a frozen gas-like structure. Subsequent experimental and theoretical works seem consistent with the general assumption that the nature of the interfaces in these materials is strongly dependent on the synthesis technique.

In particular, in nanophase metals prepared by mechanical attrition depending on the experimental conditions and on the degree of refinement of the structure reached, high density of dislocations or twins and triple junctions have been observed. In general, a reduced defects density occurs only below some critical crystallite size [4].

Mechanical spectroscopy techniques have not been extensively used so far to investigate the anelastic behaviour of nanophase metals [5-8]. The results obtained from different investigators, even if showing significant differences in the anelasticity spectra from those corresponding to similar coarse grained materials, cannot be traced back to a simple general behaviour.

In the present paper some results will be presented regarding the anelastic behaviour of nanophase aluminium (n-Al) prepared by mechanical attrition. The aim of this research is to understand the connection between anelastic behaviour and some structural parameters, such as crystallite size and interfaces, specific of the nanophase and to investigate how the microstructural evolution induced by thermal annealing affects the measured spectra.

\section{EXPERIMENTAL}

Pure aluminium powders ( $44 \mu \mathrm{m}$, Alfa products, $99.9 \%$ purity) were used for the present research. Mechanical attrition was performed by a SPEX mixer-mill model 8000 , using hardened steel balls and a 
tungsten carbide vial; the ball-to-powder weight ratio was 8 to 1 . To minimize oxygen contamination the milling treatments were carried out under argon atmosphere with an oxygen content below $5 \mathrm{ppm}$. To avoid the sticking of aluminium to the walls of the vial during the process, ethanol as a lubricant agent was added in the concentration of $0.025 \mathrm{ml} / \mathrm{g}$ of powder. After 40 hours milling a mean grain size of $20 \mathrm{~nm}$ was reached.

The consolidation procedure consisted of cold pressing the milled powders in a die with a rectangular section of $15 \times 5 \mathrm{~mm}^{2}$ under an axial pressure of about $1 \mathrm{GPa}$. In this way bar-shaped samples with a thickness of about $0.8 \mathrm{~mm}$ were obtained.

The internal friction and dynamic Young modulus measurements were performed with an inverted torsion pendulum operating in the $3-20 \mathrm{~Hz}$ range (strain amplitude $\leq 10^{-4}$ ) and by a vibrating reed technique in the $1-4 \mathrm{kHz}$ range (strain amplitude $\leq 10^{-5}$ ). All measurements in isochronal conditions were performed at a constant heating rate of $3 \mathrm{~K} / \mathrm{min}$.

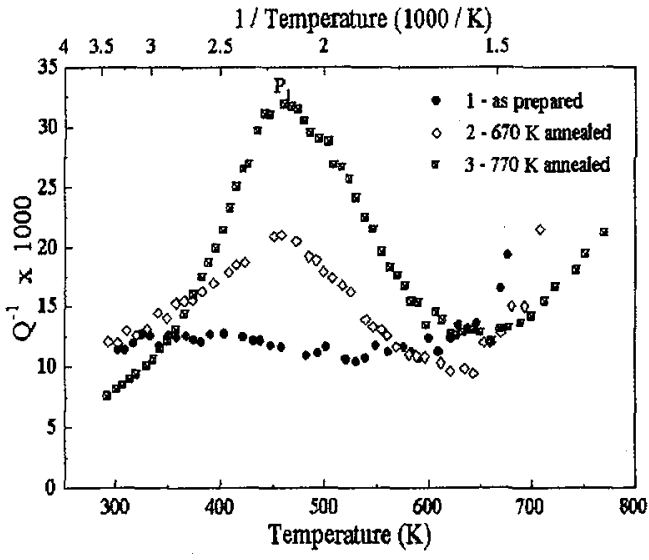

a)

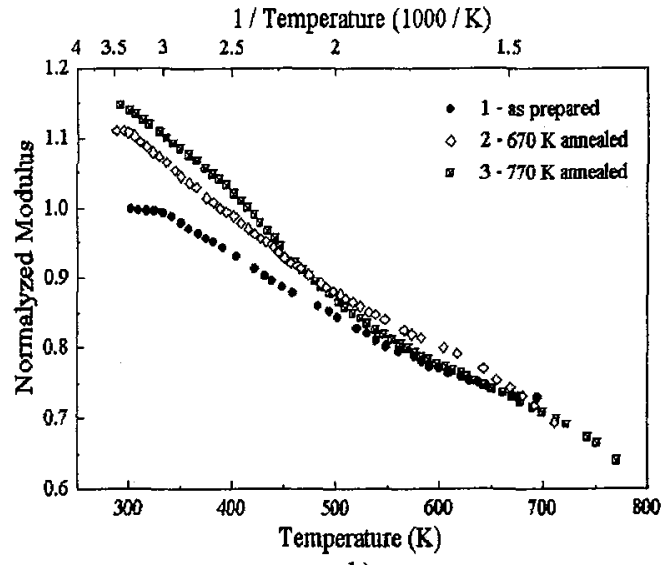

b)

Fig. 1. Internal friction $\mathrm{Q}^{-1}$ (a) and dynamic modulus (b) of $\mathrm{n}-\mathrm{Al}$ as-prepared and after annealing ( $3 \mathrm{~Hz}$ ).

\section{RESULTS AND DISCUSSION}

In fig. 1 the anelasticity spectra of a sample subjected to several heating runs are reported. Noteworthy the striking difference between the as-prepared sample (curve 1) and after heating up to $670 \mathrm{~K}$ (curve 2).

In the first case in the 300-600 $\mathrm{K}$ range an anomalous internal friction trend characterized by small and irregular fluctuations superimposed on a high background occurs; in the same temperature range the dynamic modulus exhibits a quasi-linear decreasing trend. At approximately $600 \mathrm{~K}$, a very rapid growth in the background internal friction sets on; in a parallel way a deviation from linearity is observed in the modulus curve, indicating thermally activated recovery. Two main features must be noted in curve 2 , as a consequence of thermal treatment: a significant increase (about $10 \%$ ) of the room temperature modulus and the appearance of an internal friction peak $\mathrm{P}_{1}$, centered at about $460 \mathrm{~K}(3 \mathrm{~Hz})$, accompanied by a decrease in the high temperature background damping. Further heating (up to $770 \mathrm{~K}$ ) causes a strong increase in the peak height without altering peak position and reduces both low and high temperature background, as shown in curve 3 . Anyway, it is evident that heating up to $670 \mathrm{~K}$ determines a dramatic change in the anelastic behaviour of the material; in a different manner, further annealing only refine the anelasticity spectrum without significantly altering its main characteristics.

Moreover, X-ray diffraction line-broadening analysis reveals that no appreciable grain growth occurs after the first heating run, and that only a slight increase of the mean grain size up to $40 \mathrm{~nm}$ takes place after the 
second run. On the contrary, the root mean square atomic level strain exhibits a marked reduction nearly equal to $50 \%$ and $90 \%$ after the first and second run respectively.

Let's turn our attention back to $\mathrm{P} 1$ : its activation energy and preexponential factor have been determined in analogy to the usual peak-shift technique yielding the following values:

$$
\begin{aligned}
& \mathrm{H}=(1.0 \pm 0.1) \mathrm{eV} \\
& \tau_{0}=10^{-12} \mathrm{~s}
\end{aligned}
$$

To be noticed that $\mathrm{P} 1$ height measured in flexural vibrations (fig. 2 ) is lower of about a factor 10 than when measured with the torsion pendulum; on the contrary, the modulus defect is nearly the same. A possible influence of the strain amplitude must be taken into account to explain this discrepancy.

The vibrating reed technique also allowed us to detect a narrower peak P3 located at lower temperatures, (fig. 2). Its absence at low frequency (fig. 1,3) is probably due to a partial convolution with the low temperature tail of $\mathrm{P} 1$ and to the high background damping. Fitting the experimental curve in accordance with a single-time Debye relaxation the approximate values $\mathrm{H} \sim 1.3 \mathrm{eV}$ and $\tau_{0} \sim 10^{-17} \mathrm{~s}$ are calculated.

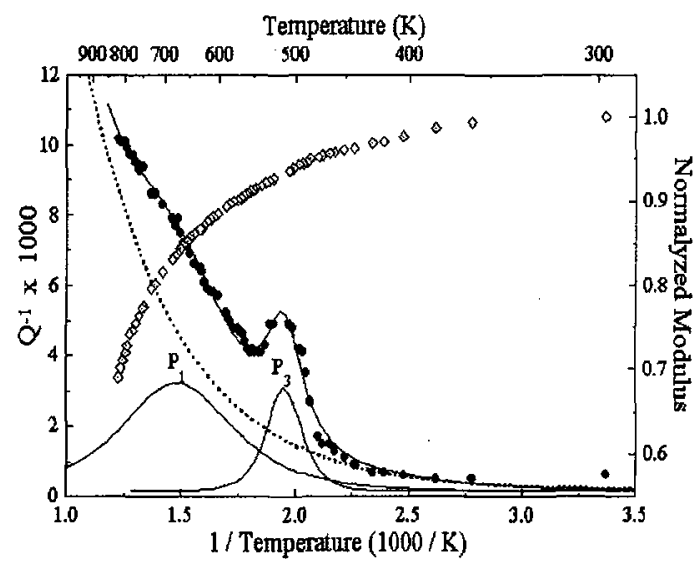

Fig. 2. Internal friction and dynamic modulus measured at $3800 \mathrm{~Hz}$ for the $770 \mathrm{~K}$ annealed sample.

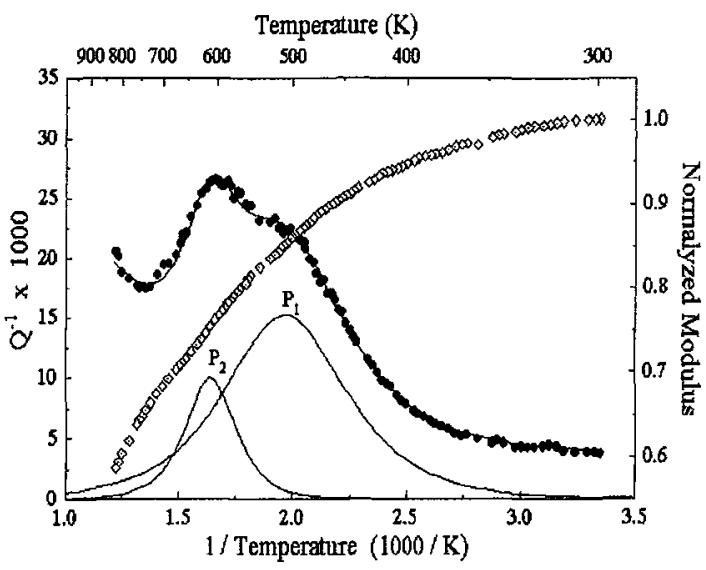

Fig. 3. Internal friction and dynamic modulus measured at $18 \mathrm{~Hz}$ after $850 \mathrm{~K}$ annealing.

Finally, fig. 3 shows the anelastic spectrum after annealing up to $850 \mathrm{~K}$; the mean grain size now exceeds $100 \mathrm{~nm}$. It is clearly observable a reduction of P1 height and the appearance of another peak P2 at higher temperature. This peak is of relaxational nature; its parameters are $\mathrm{H} \sim 1.4 \mathrm{eV}$ and $\tau_{0} \sim 10^{-14} \mathrm{~s}$.

As regards $\mathrm{Pl}_{1}$, it is interesting to observe that the relaxation strength grows appreciably when significant atomic strain reduction without appreciable grain growth occurs. The amount of modulus recovery of the order of $10-15 \%$ after annealing up to $670 \mathrm{~K}$ agrees with the previous results on $\mathrm{Al}$ [5]; it is also within the range of those observed by Weller et al. on as-prepared nanophase Pd produced by inert gas condensation and annealed up to $640 \mathrm{~K} \mathrm{[7]} \mathrm{and} \mathrm{by} \mathrm{Okuda} \mathrm{et} \mathrm{al.} \mathrm{on} \mathrm{nanostructured} \mathrm{Au} \mathrm{after} \mathrm{annealing} \mathrm{at}$ temperatures in the $450-810 \mathrm{~K}$ range [8]. Weller et al attribute this modulus recovery to an increase of the modulus at the interfaces associated with interatomic rearrangements in the grain boundary structure. On the contrary Okuda gives an explanation in terms of dislocation annihilation induced by thermal annealing. On the other hand, as observed on nanophase $\mathrm{Pt}$ [9], the microstructure evolution may be subdivided in a two-stage recovery. The first one, occurring at about $500 \mathrm{~K}$, is not linked to grain growth and involves only structural relaxation in the core of the grain boundaries. It has also been proved that $420 \mathrm{~K}$ annealing of submicrocrystalline $\mathrm{Cu}$ produced by severe plastic deformation results in a significant reduction of the internal stresses without substantial grain growth, as deduced from a strong reduction of the yield stress [10].

In addition to the results reported in fig. 1, a systematic investigation of the dependence of anelastic spectra on thermal heating shows that $620-670 \mathrm{~K}$ is a sort of critical temperature range for the transition from curve 1 to curve 2 like anelastic behaviour, meaning that heating up to lower temperatures in the 
same experimental conditions doesn't produce the same changes. It is obvious that the concept of criticality adopted here is not to be intended literally, since structural relaxation of metastable materials involves kinetic processes rather than phase transition; so we do not know which results could be obtained heating at lower temperatures for a sufficiently long time.

On the basis of these results it can be argued that the appearance of peak P1 after annealing the samples at temperatures in the $620-670 \mathrm{~K}$ range is connected to the interfacial structure evolution. Its absence in the as-prepared samples can be tentatively explained as follows: a) high structural heterogeneity and defects density result in a wide spectrum of relaxation times, giving a broad irregular damping without a well defined anelastic relaxation; b) interfacial regions initially characterized by a gas like atomic configuration [2] exhibit a viscoelastic type behaviour.

Also on the basis of a previous research [5], we can assess that a broad internal friction peak P1 centered at about $460 \mathrm{~K}(3 \mathrm{~Hz})$ is characteristic of nanometer-sized aluminium prepared by mechanical attrition; P1 appearance depends on thermal and also mechanical treatments, indicating the need for microstructure reordering and stabilization. Its activation energy close to $1 \mathrm{eV}$ is substantially lower than self diffusion activation energy in bulk aluminium.

$\mathrm{P} 2$ activation energy and position (fig. 3) suggest that $\mathrm{P} 2$ could be reasonably identified with the intermediate temperature peaks (ITP) observed by different authors in the $0.6 \div 0.7 \mathrm{Tm}$ range on polycrystalline aluminium of comparable purity [11]. On the basis of this hypothesis, the intriguing question regards the absence of $P 2$ when the grain size is in the 20-40 nm range: we should indeed explain the existence of a sort of critical grain dimension Dc under which P2 relaxation strength rapidly falls down. Taking into account the reported dependence of ITP on intragranular dislocation dynamics [11,13], Dc represents the dimension at which the activity of dislocations inside the grains is strongly reduced [12]. Further measurements are in progress to clarify this point.

\section{CONCLUSIONS}

A well defined relaxation peak $P 1$ centered at about $460 \mathrm{~K}(3 \mathrm{~Hz})$ with an activation energy of $1.0 \mathrm{eV}$ is observed in $\mathrm{n}-\mathrm{Al}$ after thermal annealing without substantial grain growth. This peak seems to be characteristic of $\mathrm{n}-\mathrm{Al}$ prepared by mechanical attrition and its appearance is probably related to interfacial structure stabilization and reordering. After $850 \mathrm{~K}$ annealing the mean grain size in the sample exceeds 100 $\mathrm{nm}$; another relaxation peak $\mathbf{P} 2$ appears at higher temperatures. Its activation energy and position suggest the identification with the intermediate temperature peaks observed in polycrystalline aluminium.

\section{References}

[1] R.W. Siegel and G.E. Fougere in Nanophase Materials, C. Hadjipanayis and R.W. Siegel Eds. (Kluwer Academic Publishers, 1994) pag 233.

[2] T. Haubold, R. Birringer, B.Lengeler and H. Gleiter, Phys. Lett. A 135 (1989) 461.

[3] T. Haubold, W. Krauss and H. Gleiter, Phil. Mag. Lett. 63 (1991) 245.

[4] J. Wang, D. Wolf, S.R. Phillpot and H. Gleiter, Phil. Mag. A 73 (1996) 517.

[5] A. Al Sadi, E. Bonetti, P. Mattioli and G. Valdrè, J. All. Comp. 211/212 (1994) 489.

[6] E. Bonetti and G. Valdrè, Phil. Mag. B 68 (1993) 967

[7] M. Weller, J. Dihel and H.E. Schaefer, Phil. Mag. A 63 (1991) 527

[8] S. Okuda, F. Tang, H. Tanimoto and Y. Iwamoto, J. All. Comp. 211/212 (1994) 494.

[9] A. Tschope and R. Birringer, Acta Metall. Mater. 41 (1993) 2791.

[10] V.Y. Gertman, R. Birringer and R.Z. Valiev, Phys. Stat. Sol. a 149 (1995) 243.

[11]J. Woirgard, A. Riviere and J. De Fouquet, J. de Physique 42-C5 (1981) 407.

[12]R.W. Siegel and G.E. Fougere, NanoStruct. Mater. 6 (1995) 205.

[13]A. Rivière and J. Woirgard, J. All. Comp. $211 / 212$ (1994) 144. 